\title{
Humilhação social: uma reflexão sob o ponto de vista psicanalítico
}

\author{
Social humiliation: a reflection from the \\ psychoanalytical point of view
}

André SIROTA

\section{Resumo}

Este artigo traz uma reflexão sobre a questão da humilhação social, compreendida como manifestação perversa, a partir da consideração clínica detalhada de reuniões entre pais, professores e gestores educacionais, sob o ponto de vista psicanalítico. Aponta a importância de considerar os complexos modos como se articulam dimensões afetivo-emocionais individuais, conscientes e inconscientes com a dinâmica do viver coletivo.

Unitermos: Ambiente escolar. Comportamento moral. Psicologia educacional.

\begin{abstract}
This article introduces a reflection about the question of social humiliation, understood as a perverse manifestation, based on detailed clinical considerations from meetings with parents, teachers and educational administrators, from a psychoanalytical point of view. It points to the importance of considering the complexways in which the conscious and unconscious individual affective-emotional dimensions are articulated with the dynamic of collectiveliving.
\end{abstract}

Uniterms: School enviromment. Anticocial behavior. Educational Psychologist.

Um começo de ano letivo diferente foi a circunstância que me possibilitou ouvir a mercurial(2) nitidamente desacreditada de um delegado de ensino e as reações que provocou. Quem faz uso da palavra desta forma em um contexto social humilha publicamente seus interlocutores, e é importante lembrar que este tipo de conduta resulta, sem dúvida, de experiências precoces de humilhação vividas no grupo familiar (Sirota, 1995, 1998a; Stoller, 1984). Quando um ator institucional serve-se mais ou menos regularmente deste tipo de desqualificação, pode-se estabelecer a hipótese de que somente aprendeu e integrou a cultura dominante da organização a que pertence (Enriquez, 1992). Entretanto, no caso desta ocorrência,

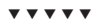

1 Université de Paris X - Nanterre. LASI, 200, Avenue de la République, 92001, Naterre, France.

2 "Antigamente, nome de uma assembléia do parlamento de Paris que acontecia na primeira quarta-feira após o dia de Saint-Martin e na primeira quarta-feira após a semana de Páscoa, na qual o primeiro presidente falava contra os enganos e as desordens que se cometiam na administração da justiça" (Chicago, Littré, (1987), Tome 4, p.3839). Por extensão, uma mercurial é uma alocução inaugural pronunciada por um membro do Ministério Público por ocasião da retomada anual dos trabalhos das cortes e tribunais após as férias de verão. Ela significa uma chamada à ordem das coisas e ao espírito das leis face a diferentes desordens, reais ou supostas, induzidas pela vacância estival da instituição. 
por falta de dados, não é possível decidir categoricamente se a conduta atual resulta unicamente do peso da influência externa ou se serve consideravelmente a um roteiro ou sistema individual de defesa relativo a experiências pessoais de humilhação social precoce.

Expressão de uma problemática individual ou organizacional, a tendência reiterada à desqualificação perversa deve ser compreendida como a defesa última de um sujeito, uma categoria de atores ou seus representantes face a uma ressonância provocada pela confrontação com a configuração social que atualmente vivem como ameaçadora e capaz de reativar antigas cenas de desaprovação, seja consciente ou inconscientemente. Na cena externa atual, o sujeito individual ou o coletivo, a hierarquia ou o representante de um estrato social, por exemplo, temem o risco de contato com sua intimidade ou com o que os fundamenta psíquica e socialmente. Receiam o ressurgimento de um acontecimento antigo para o indivíduo ou de uma revelação sobre a origem de sua formação social, que seria o reverso de um mito para uma categoria de atores, porque estes foram registrados como catastróficos ou inomináveis.

Esta conduta verbal, quando se repete, pertence ao domínio do que chamo de perversão psicossocial (Sirota, 1995, 1998a), outro nome para designar a perversão narcísica (Eiguer, 1989, 1995; Racamier, 1970, 1992). Revela uma necessidade irreprimível de se proteger e de se satisfazer no âmbito de uma cena social (institucional, profissional, associativa ou política) à custa do outro. Por esta conduta, desprezando eventualmente o direito, as leis ou a mais elementar cortesia, seu autor designa o outro, um indivíduo ou uma categoria de indivíduos ou de atores, suas idéias ou expressões, como ilegítimas ou indignas. Este tipo de intervenção ocorre freqüentemente de forma inesperada e é como se violasse, por arrombamento, o enquadre, o espaço e os registros de fala, bem como os objetos em discussão. 0 autor desfere sua forma de pensar como se fosse comum, majoritária ou mesmo como se fosse a única autorizada.

Conforme o caso, a alteridade é localizada em um ou em vários indivíduos, em um grupo ou categoria de atores sociais, ou ainda em um grupo étnico. O autor

558 de tal ataque perverso atribui ao outro, de uma forma mais ou menos peremptória, difamante e fabuladora, motivações ou pensamentos maus, inconfessáveis. Sugere que aqueles que ele toma por alvo não estariam em seus devidos lugares no espaço social presente, mas seriam, ao contrário, usurpadores, ou teriam cometido atos repreensíveis dos quais seriam os únicos culpados. Pelo mesmo movimento, o atacante se outorga a autoridade e a competência de distinguir o joio do trigo, autorizando-se uma ordem superior e universal que não se submete a discussão alguma, que Ihe permite que ele dissimule seu desejo e exima-se de culpa (Chasseguet-Smirgel, 2006). A estes que são assim mostrados como "outros" e separados totalmente do mundo dos cidadãos, notifica-se que perderam a dignidade por sua própria culpa, tendo eles próprios se desqualificado. Assim, logicamente não teriam direito à palavra, só Ihes restando permanecer calados e obedientes.

Quando um indivíduo pessoalmente envolvido por esta problemática se serve da arte da desqualificação perversa (Eiguer, 1989; Racamier, 1992), persegue dois objetivos sem escrúpulo. Por um lado, quer interromper um fenômeno de ressonância por meio do qual se sente em grande perigo entre seu mundo interno e o mundo dos objetos externos atuais. Por outro lado, se consegue obter esta interrupção, modifica o quadro grupal, instalando concomitantemente um roteiro organizado só por ele. Na verdade, ao desqualificar o outro, desloca o centro da atenção para um alvo tomado como mau objeto, para que seus estratagemas e suas fraquezas, ou os da instituição por ele representada, não sejam percebidos. E, ainda, ao desviar assim uma pessoa ou um grupo de sua tarefa básica, espera torná-los improdutivos, o que validaria sua desqualificação. Para isso, ele pode intervir com freqüência no espaço grupal para bloquear o pensamento e evitar que, durante este tempo, a instância reunida realize sua tarefa. Trata-se de um estratagema de esterilização que, ao impedir a ação, transforma a atividade de um grupo em agitação vã e a energia de seus membros em tensão negativa. Finalmente, ainda que este estratagema seja desvendado e que a operação de desvio venha a fracassar, o tempo consagrado a descrever as coisas e reajustar o grupo não deixa de ser tempo"ganho" para o atacante perverso, no sentido de que luta contra sua própria aniquilação. 
Este quadro bastante sintético das condutas psicossociais perversas e de seus efeitos reúne diferentes traços que nem sempre estão simultaneamente presentes. Nem toda conduta perversa emana de um sujeito perverso. Não é perverso quem quer. Na situação relatada abaixo, não se pode qualificar de perverso o autor da desqualificação. Talvez esteja impregnado por uma cultura hierárquica que aprendeu a utilizar.

\section{Primeiros dias de setembro em um colégio}

Dos setenta professores, nove não compareceram ao início das aulas; dentre eles, cinco tinham sido designados professores coordenadores pelo diretor do colégio. O cargo de secretário não fora preenchido. Contavam-se quatro vigilantes para mil e cem alunos, em um estabelecimento que fora construído para oitocentos. A maioria das salas do primeiro andar dos edifícios não estava disponível; o fim das obras, iniciadas em agosto, fora anunciado para 10 de setembro. No dia do pré-reinício das aulas, o diretor entregou aos professores os horários que preparara no computador com um programa que não dominava. Esses horários comportavam um grande número de "janelas", ou seja, cada classe contava com muitas horas de permanência no estabelecimento. Para compor classes e equipes de professores, não foram levados em conta projetos pedagógicos que já existiam e que, portanto, não puderam ser implementados. Por exemplo, uma mesma equipe de professores não pôde acompanhar, como fora previsto, durante dois anos consecutivos, os alunos com dificuldade escolar.

Desde o final do ano letivo, em junho, pressentindo o que iria acontecer, os professores propuseramse colaborar para estabelecer a grade de horários. 0 diretor declinou desta oferta, alegando suas prerrogativas. No decurso do ano anterior - seu primeiro ano neste colégio - havia multiplicado erros, por vezes com alguma violência para com os alunos, que não se sentiam seguros quando o viam. Professores, pais de alunos e representantes da comunidade foram confrontados com sua falta de cortesia elementar.

Diante da impossibilidade de comunicar-se com ele, o diretor adjunto precedente pediu insistentemente sua transferência. No meio do ano anterior a este começo de ano letivo, o adjunto foi transferido, mas não substituído. O cargo continuou vago. Constatando a impossibilidade de que as aulas começassem na data normal, os professores tomaram a iniciativa de uma recomposição dos horários e pediram ao diretor que transferisse o início das aulas para alguns dias mais tarde. Já a partir da segunda-feira à noite, data do pré-reinício das aulas, os professores sugeriram aos pais de alunos que escrevessem ao diretor da delegacia de ensino para descrever a situação e pedir apoio. Tais são os elementos mais importantes que caracterizam este reinício das aulas.

Na quinta-feira pela manhã, aconteceu uma assembléia geral do conjunto dos funcionários do estabelecimento. Fui convidado a participar na qualidade de pai de aluno. Ao final desta reunião, pedi discretamente para falar com alguns professores, a fim de verificar a exatidão dos dados coletados por telefone e citados na carta que eu havia preparado para o diretor da delegacia de ensino. Ao invés de deixar que a assembléia se dispersasse, o professor, com um olhar, reteve os participantes. Fui, então, apresentado por ele como presidente da seção local da Liga dos Direitos do Homem, e não como pai de aluno. A seguir, convidoume a proferir algumas palavras. Tomado de improviso, li o texto da carta redigida para o diretor da delegacia de ensino, pedindo aos membros desta assembléia que me corrigissem quanto aos fatos, mas informando-os que eu me reservaria a liberdade das análises.

Para minha surpresa, pois eu não estava de forma alguma mobilizado sobre as dimensões transferenciais da situação, o que eu li teve o efeito de interpretação do sofrimento deles e ressoou como uma marca de reconhecimento da situação impraticável deste reinício de ano letivo. Eles esperavam este reconhecimento por parte da delegacia de ensino, que não mostrava senão uma recusa da realidade. Com efeito, segundo o diretor, o inspetor de ensino encarregado da "vida escolar"teria declarado que "a coisa não ia tão mal assim"e anunciou que haveria cortes de salário caso as aulas não se iniciassem. Enquanto a reunião começava a se dispersar, ficou-se sabendo que este inspetor pedira ao conjunto dos funcionários para se reunirem na sexta-feira, dia seguinte, às nove horas. Conseguira liberar uma diretora adjunta proveniente de outro estabelecimento; queria alocá-la para este colégio, graças à reunião. Os professores me convidaram a tomar parte. 
Quando cheguei, precisamente às nove horas, para a reunião da sexta-feira, a sala já estava repleta. Havia mais de noventa pessoas. Dirigi-me para um assento livre na primeira fila. Vendo-me pela primeira vez, o diretor veio imediatamente até mim e me perguntou o que eu representava lá. "Sou pai de um aluno", respondi-lhe. Perguntou-me se fui eleito para o Conselho de Administração do Estabelecimento. Como este não era o caso, disse que não podia permanecer. Levantei-me e dirigi-me para a porta, mantendo-me alguns instantes em pé, em grande expectativa, entre a cadeira vazia e o limiar da porta. Durante este breve instante, ele se dirigiu ao inspetor e the pediu sua opinião. O inspetor concordou que eu permanecesse. Outros pais de alunos, eleitos ou não nas instâncias, estavam igualmente presentes na sala. Entretanto, tendo chegado bem antes do que eu e se instalado no fundo da sala, não podiam ser facilmente distinguidos. 0 inspetor abriu a reunião e disse o seguinte:

É uma situação excepcional esta aqui, um colégio que não começa as aulas no dia estabelecido para início do ano letivo, e que, três dias após esta data, não funciona ainda. Isto não é banal. Vocês entendem que considero esta situação de forma muito séria.... Em resumo, vocês brincam defazer greve. Esta situação não pode continuar. ... Vocês contestam. Recusaram os horários estabelecidos pelo diretor. As férias jáacabaram neste momento. Vocês não estão mais na praia. ... Vocês refazem os horários. Vocês se divertem, é preciso acabar com este jogo, assegurar reinício das aulas, e que cada qual retomeseu lugar. Vocês não tinham diretor adjunto. Vim aqui para justamente instalar a Sra. N. em suas funções de adjunta. Não écomum que um inspetor se desloque para isto; esta situação se deve ao clima deste estabelecimento. Se o clima não estivesse como está, eu não estaria aqui. Se vocês não cooperarem de forma satisfatória com a Sra. N.e, em quinze dias, ela me disser que não pode trabalhar neste colégio e que quer voltar a seu antigo estabelecimento, não poderei me opor. Levando em conta sua carreira e experiência, a Sra. N. pode esperar conquistar um posto de direção em um grande estabelecimento parisiense no próximo ano letivo. Aqui ela está comissionada e guarda seu posto no estabelecimento do qual provém. Ela iniciará suas funções aqui na próxima segunda-feira pela manhã. ASra. N. seráresponsável pela distribuição dos horários. Nenhum horário poderá ser implantado sem que a Sra. N. o ten ha revisto e validado. Após esta reunião, a Sra. N. poderá estar com vocês por algum tempo para que vocês the forneçam os documentos necessários. Enfim, quero precisar que a Sra. N. se encarregará da vida interior e será responsável pelas tarefas administrativas e pedagógicas do colégio e o Sr. $X$., diretor, encarregar-se-á das relações externas. Espero quevocês colaborem com a Sra. N. Se ela for embora, não encontrareininguém para substituí-la ${ }^{(3)}$.

Ao passo que cada idéia emitida soava como uma salva contra os professores, provocando clamores sucessivos de indignação, o inspetor continuava imperturbável sua admoestação, com suas numerosas redundâncias, fazendo-a durar vinte minutos. O que é que se pode fazer quando se é assim designado como irresponsável: calar-se, ir embora, revidar a humilhação?

Finalmente, o inspetor concluiu sua fala seguindo o protocolo: "Se vocês têm perguntas, podem fazê-las."

Tal estratégia verbal (Sirota, 1998b) por parte de um membro elevado da hierarquia coloca a questão dos objetivos implícitos e explícitos deste tipo de reunião e das expectativas implicadas.

Durante diferentes trocas com os professores, estes se mostraram preocupados em assegurar um retorno às aulas organizado. Necessitavam que o inspetor reconhecesse a situação caótica do estabelecimento e compreendesse os motivos da dificuldade da volta às aulas, assumindo a parte de responsabilidade que cabia à instituição. Os professores esperavam do inspetor que este desse seu apoio ao trabalho de elaboração da grade de horários, que se engajasse em nomear professores em um prazo razoável para os postos que estavam livres, que levasse em conta os efetivos reais do estabelecimento e estudasse a possibilidade de que novos vigilantes fossem nomeados. É bom lembrar que este colégio, situado no subúrbio de Paris, experimentava a maioria dos problemas que hoje se tornaram ordinários. Enfim, os professores esperavam que seu inspetor tomasse atitudes específicas em relação ao diretor que ocupava este cargo, a fim de conter, na medida do

\section{$\operatorname{cov} \operatorname{ser}$}

3 Esta abordagem do problema durou mais de vinte minutos, em uma reunião de menos de uma hora. Transcrevi-a quase textualmente, mas de forma 560 condensada. 
possível, seus comportamentos perturbadores. Este era, de fato, o ponto mais delicado da situação.

Quanto ao diretor, narcisicamente ferido e centrado na vigilância de seu recurso a prerrogativas, durante todo este período apareceu exclusivamente levado por uma necessidade de restauração. Não parava de repetir, como se estivesse traumatizado, a quem quisesse ouvi-lo: "Trata-se de manter a dignidade".

Um dos objetivos do inspetor era assegurar o início de um ano letivo nos melhores prazos, criando condições institucionais favoráveis à instauração de uma boa cooperação entre a nova diretora adjunta e o conjunto dos professores. Entretanto, sua forma de se dirigir aos professores mostrava que buscava, consciente ou inconscientemente, outro objetivo. Parecia querer ser "eqüitativamente" severo. Para contrabalançar o que acabara de dizer ao diretor, ou seja, que este deveria se ocupar no futuro somente de "coisas externas", quis humilhar os professores que, nos dias precedentes, recolocaram suas carências ao diretor. Ora, para tratar com consideração o diretor não seria necessário humiIhar os professores. Para além destas circunstâncias, parece que o inspetor tinha outro alvo: o de dispersar um coletivo contestador, reinscrevendo os indivíduos em uma ordem e no ritual da tradição hierárquica, característica das esferas político-administrativas da educação nacional. Para reinstalar a autoridade, que julgava estar escarnecida, fez ameaças por alertas e ordens explícitas, tentando redirecionar cada qual a uma culpabilidade individual, sugerindo uma analogia entre a recomposição dos horários e as brincadeiras na praia das despreocupadas crianças no verão.

Assim que a fala do inspetor terminou, havia mãos levantadas para pedir a palavra, dentre as quais a minha e a do professor que eu conhecia. $O$ inspetor passou-Ihe a palavra e ele a transferiu imediatamente para mim, tão rapidamente quanto um esportista passa o bastão para seu colega no esporte.

Seguem minhas palavras:

Senhor inspetor da academia, eu agradeço por aceitar que eu participe desta reunião, embora eu não esteja engajado na vida do colégio. Aproveito esta posição de exterioridade para dizer algumas palavras sobre a noção de greve, de contestação, de férias e de clima que osenhor acabou de empregar. Da forma como compreendo a situação, estas noções não me parecem apropriadas para caracterizá-la. Na verdade, estas noções, ao invés de descrever as dificuldades atuais, visam desqualificaruma categoria de atores, ou seja, os professores. O senhor os designa como culpados da situação caótica. Ameaçaos de abandoná-los caso persistam em suas criancices. Ora, aquilo que se passa em uma organização é o resultado complexo da ação e da inércia misturadas aos diferentes atores que a constituem. Fiquei surpreso com sua fala. Osenhorme permita pensarquenãoéumaboa maneira de começar uma reunião, sobretudo quando esta deve desembocar em diálogos e permitir que se ultrapassem, através de um acordo, as dificuldades do início do ano letivo em um estabelecimento escolar.

A seguir, os professores tomaram a palavra. Uma professora levantou-se e disse dignamente:

Senhor inspetor, o senhor me humilhou pessoalmente falando da forma como o fez. Esta maneira de se dirigir a mim, certamente, da mesma forma que a todos professores aqui presentes, não se justifica. Eu me pergunto a quem o senhor pensava dirigir-se ao falar assim.

Muitos afirmaram então estar igualmente surpresos com a fala humilhante do inspetor, dizendo que ele estava enganado quanto ao lugar e ao público a quem se dirigia, que não se deve dirigir assim nem a crianças que cometeram erros. Durante esta fase, os professores retomaram palavra por palavra e em tom neutro certo número de expressões pronunciadas pelo inspetor ou pelo diretor nos dias anteriores, para fazê-lo sentir a responsabilidade pelos estratagemas que usara para desviar a atenção e o sentido. Face aos efeitosbumerangue de suas palavras, o inspetor e o diretor não cessavam de responder "Eu não quis dizer isto" ou "Eu nunca disse isto."

Na seqüência, os professores disseram o quanto se rejubilavam pela chegada da Sra. N., que desejavam conhecer e com quem estavam prontos a cooperar imediatamente, assegurando que lhe forneceriam todas as informações necessárias assim que a reunião acabasse.

Um deles acrescentou, voltando-se para a nova diretora adjunta: "Pensamos, Sra. N, que a senhora sentirá interesse e prazer suficientes para desejar permanecer durante um bom tempo conosco".

Enfim, outros professores, funcionários e pais de alunos eleitos evocaram os diferentes problemas e falhas no funcionamento do estabelecimento, que estavam 
desde o ano precedente sem solução ou sem resposta, após várias cartas ou tentativas de resolução.

Então, um professor disse, sem abandonar o bom humor:

Senhor inspetor. Noto que, ao terminar sua fala inicial, o senhor disse, com relação à divisão de responsabilidades entre o diretor e a diretora adjunta, que esta última se encarregaria dos assuntos internos e ele, dos assuntos externos. Observo que o senhor terminou muito bem sua introdução nesta reunião. Terminando-a como o fez, o senhor havia perfeitamente compreendido qual a causa de nosso sofrimento neste estabelecimento, e nós Ihe agradecemos.

O inspetor não respondeu, mas as variações de sua fisionomia mostraram que se sensibilizou com o que ouviu. Ninguém riu, como se cada qual houvesse compreendido que não se deveria jogar simetricamente no terreno do jogo que o inspetor quisera instalar: ou seja, o do ataque desqualificador (Sirota, 1998a). Depois que todas as categorias de atores se expressaram, o inspetor transmitiu informações em resposta a certas dificuldades apontadas e orientou as demandas precisas para as instâncias competentes. Certificou que estaria atento à nomeação de professores que realmente pudessem assumir seus postos nos menores prazos possíveis. Às dez horas, encerrou a reunião.

Professores se reagruparam, uns próximos à diretora adjunta, outros em volta do inspetor. Durante uns quinze minutos, em uma sala em plena efervescência onde todo mundo falava em pequenos grupos, desloquei-me de um grupo a outro, olhos e ouvidos etnográficos. Alguns professores perguntaram ao inspetor porque ele havia se dirigido a eles daquela forma; $\mathrm{e}$ lá, em pequenos grupos, não negou que havia dito as coisas de que estava sendo acusado. Mudou seu sistema de defesa declarando ter optado por "palavras espirituosas", ou invocando uma simples vontade de vê-los reagir. Alegou que o que dissera não correspondia ao que verdadeiramente pensava. Seu tom havia se tornado cordial.

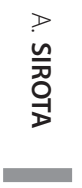

O relativo distanciamento que o inspetor manteve em relação ao diretor, bem como a nomeação urgente de uma diretora adjunta experiente, satisfizeram os professores em diversos planos. Deste modo, poderiam trabalhar efetivamente. $O$ diretor, limitado a funções

562 secundárias, tornar-se-ia menos perturbador para a vida do estabelecimento. Enfim, os professores sentiram-se confortados na legitimidade de sua ação coletiva. Conseqüentemente, passaram a ter motivos para experimentar um certo prazer, por terem tido coragem de se mobilizar, recusar condições inaceitáveis para o início de ano letivo e também por terem se mobilizado em prol de um projeto de ação em comum, o que não é tão freqüente. Durante uns bons quinze minutos, neste momento "pós-reunião", todo mundo começou a falar com todo mundo, cada um circulou de grupo em grupo. As conversas ocorreram em uma atmosfera quase festiva. As colocações do inspetor poderiam ter agravado as tensões se, da parte do pessoal, dois perigos não tivessem sido evitados: o de se sentirem individual e coletivamente covardes e envergonhados, por nada terem dito para denunciar este ato de humilhação pública (Green, 1983; Kaës, 1976, 1996), ou o de caírem na provocação emocional, servindo-se, eles também, de palavras excessivas e desestabilizadoras, ou seja, o risco de se conduzirem para um contra-ataque perverso (Anzieu, 1975; Bion, 1961).

As últimas colocações da professora provocaram júbilo. Esta, entretanto, permaneceu discreta, como uma leve onda na superfície da água, imperceptivelmente perturbada. Os professores e os outros ouvintes presentes abstiveram-se de rir. Se o tivessem feito, teriam assim separado uma parte da assembléia da outra e comprometido o trabalho de restauração dos laços com a hierarquia. Como a manobra do inspetor foi denunciada e desmontada, o diálogo com ele foi mantido e a cooperação com a nova diretora adjunta foi melhor engajada.

Se fiz um julgamento de valor, foi baseado na observação de uma seqüência precisa de comportamentos, passível de ser observada no aqui e agora. Não coloquei em dúvida o sentido das responsabilidades deste inspetor, nem dos inspetores de forma geral, nem pronunciei asserção malévola. Não se pode, portanto, objetar que, por meu lado, desqualifiquei o inspetor. Não há homologia entre minhas colocações e as dele. Nem todo julgamento de valor constitui uma "desqualificação perversa", felizmente - caso contrário, seria preciso concluir, por exemplo, que a escola é um espaço permanente de desqualificação perversa ou destrutiva dos alunos ou dos próprios professores, levando em conta o lugar da avaliação no sistema educativo e formativo. 
Quando, na véspera, o professor que conheço apresentou-me a seus colegas como presidente da seção local da Liga dos Direitos do Homem, senti-me constrangido e surpreso. Por esta razão, procurei imediatamente afastar esta etiqueta, afirmando que estava lá na qualidade de pai de aluno. Ora, passado o primeiro momento, ficou bem claro que este professor fora levado por boa intuição. O título pelo qual me nomeou colocou-me em uma situação de terceiro, extrínseco ao grupo de professores, posição certamente mais favorável a eles do que a simples qualidade de pai de aluno.

Esta situação relança a reflexão sobre o que permite que um participante ou um psicossociólogo reconheça uma desqualificação perversa cometida por um ator e, a seguir, encontre uma forma correta de assinalar e frear os efeitos. Para que se possa dizer alguma coisa que tenha função de interposição protetora é preciso, sem nenhuma dúvida, não estar colado nem a um lado nem ao outro. Esta posição é difícil de ser mantida quando se é um participante comum do grupo, pois acirra processos de rivalidade, que são um dos nós da vida em grupo. Além disso, não é possível ocupar lugar de terceiro apenas por iniciativa própria, mesmo quando se está qualificado para tal em termos de formação e competência.

A posição de terceiro deve ser reconhecida e investida como tal por aqueles com quem colabora aquele que a ocupa. Para inspirar a confiança necessária e sustentar tal lugar aos olhos dos outros, um psicossociólogo deve-se mostrar vigilante, sobretudo com relação a tendências que podem seduzir e lisonjear as partes cínicas de cada um (Eiguer, 1995). Uma das responsabilidades profissionais essenciais de um consultor externo consiste, sem dúvida, em manter e exercer sua liberdade de pensar e de nomear, sem esperar qualquer desqualificação perversa, venha de onde vier, quer se apresente como uma simples tirada ou acondicionada em uma fórmula brilhante, já que o perverso social é, com muita freqüência, inteligente e capaz de fazer bom uso da linguagem.

Humilhando os professores, o inspetor, enquanto membro de uma área cultural ou sujeito social (Barus-Michel, 1987) de uma comunidade hierárquica, foi movido por uma lógica institucional. Além disso, seguiu o objetivo inconsciente de privá-los do prazer partilhado que poderiam sentir face ao reconhecimento implícito da legitimidade de suas análises e da ação coletiva (Sirota, 1998a). Se uma administração toma medidas pertinentes, sob efeito de certa relação de força, sua cultura o impede de reconhecer que tal movimento foi benéfico e até mesmo necessário. Ora, barrar o acesso ao prazer compartilhado, em conseqüência de uma ação coletiva e construtiva, é privar o ser humano de uma parte construtora de sua humanidade e de sua sociabilidade. É, portanto, atacar os sentimentos e os laços comunitários dos quais os chefes não poderiam se considerar isentos, ainda mais no âmbito de uma organização constitutiva de um sistema democrático, como o é a escola.

Entretanto, a cultura hierárquica repousa sobre o dogma da infalibilidade desta. Em suas bases coletivas inconscientes, o outro não é reconhecido como parceiro. Para seus depositários, esta cultura autoriza a idéia de que o poder institucional delegado a uma pessoa repousa sobre uma espécie de dignidade superior desta. A dignidade superior seria magicamente afetada pela simples nomeação em um estatuto de autoridade. Por esta razão, o poder institucional delegado a uma pessoa não se pode fiar no reconhecimento de saberes próprios a funções de direção, tampouco na capacidade de assumir papéis estruturantes necessários a uma organização educativa, por exemplo. Todos os membros da hierarquia podem ser instrumentos ou reféns e, por vezes, cúmplices desta cultura, sem que disso estejam conscientes, enquanto não se derem ao trabalho de refletir e se liberar. Ora, as condições desta cultura são, "por natureza", destrutivas, pois entretêm um processo coletivo de desqualificação perversa.

Superestimar o valor ou a competência dos titulares de cargos hierárquicos e da hierarquia em geral é fazer deste conjunto uma categoria superior em si, uma entidade perfeita, ou seja, não humana. Na verdade, suspeitar a priori que a hierarquia seja completamente má traduz um processo de idealização e a existência de uma espera inconsciente de perfeição e de uma espécie de impossibilidade de aceitar o outro ou a realidade exterior por aquilo que são. Este traço perverso, quando sustentado por uma cultura de organização, constitui uma característica estruturante que, todavia, não provoca efeitos sociopatológicos, na medida em que não é a lei que se faz como terceiro, mas sim a referência a uma dignidade mitologicamente superior, da qual alguns se 
servem para aniquilar os outros. Pode-se considerar e mesmo temer que aí resida uma fonte importante da violência induzida pelas instituições escolares e educativas à custa de seus membros, que podem desposar pouco a pouco suas formas e com elas se identificar.

Não há lei suficiente na escola. A lei é o que constitui ligação com o outro. É também o outro, aquilo a que estamos todos submetidos contratualmente. Na vida cotidiana de uma escola, a lei se traduz por instituições concretas e meios sociais explícitos que organizam a distribuição dos lugares e dos papéis entre os adultos, os quadros educativos, as crianças e os jovens. A lei estipula aquilo a que cada um se obriga em relação ao outro. Levando em conta o lugar do indivíduo no sistema, ela sugere o que é esperado legitimamente dos papéis recíprocos. Quando a questão da lei e da relação com esta não é escamoteada, traduz-se por dispositivos, condutas de formação ou por instruções pedagógicas explícitas e praticáveis, instaurando relações de trabalho formativo entre professores e alunos.

$\mathrm{Na}$ realidade, o trabalho com professores e quadros educativos e de direção dos estabelecimentos escolares mostra, com freqüência, que a questão da inscrição institucional continua sendo um tabu. Por exemplo, o quadro que representa o projeto de estabelecimento é vago, o que permite aos atores apresentar belos envelopes vazios e facilita que a administração da educação nacional não se engaje realmente nas diretrizes por ela formuladas. Enquanto todo mundo se queixa das condutas das novas gerações, que não teriam mais valores nem pontos de referência, não existe regra que obrigue os diferentes quadros de professores a construírem juntos as formas e condições coletivas e institucionais de se encarregarem da missão de sociabilização. Ora, sem uma participação dos atores na construção do quadro, o sentido do processo de sociabilização permanece insuficientemente elaborado, e a função de sociabilização não pode ser assegurada. A educação para a cidadania não pode ser promovida caso seja considerada um objeto de aprendizagem ou uma nova matéria no programa.
A postura acrítica no contexto institucional da escola pode ainda ser observada no momento em que o professor é recrutado. Para efetuar esta passagem, ele não assina nenhum contrato de trabalho com o Ministério da Educação Nacional no qual figure claramente o que o ministério espera dele, nem qual deve ser seu engajamento em termos de contrapartida. Entretanto, uma circular bastante interessante foi publicada no Boletim Oficial da Educação Nacional(4). Trata-se de um texto de orientação consistente que reconhece e formula com precisão a existência das diferentes missões do professor do ensino fundamental, do colegial tradicional ou do colegial técnico ou profissional. É preciso reconhecer que as resistências à redefinição do posto de trabalho de um professor atravessam diferentes categorias de atores. As manifestações de professores contra a implantação de algumas das proposições emanam do"Rapport Meirieu" sob pretexto de preservar a cultura e a qualidade do ensino de que constituem prova. Enquanto, no plano individual, numerosos professores desenvolvem práticas inovadoras para se adaptar aos alunos reais, alguns deles resistem a oficializar seu novo trabalho, como se não pudessem mudar senão preservando no fundo deles mesmos a figura do bom professor de outrora.

Enfim, os regulamentos internos colocam com freqüência os alunos e mesmo suas famílias em uma posição de dignidade inferior, e dão impressão que somente eles é que são submetidos a regras e a leis. Ora, o regulamento interno de uma organização, particularmente quando ela se chama"comunidade educativa", deve ser redigido incluindo todos os membros.

Os professores têm um papel institucional ou de enquadramento, ou seja, uma função de suporte eles representam e são fiadores da lei. Enquanto a instituição e o lugar necessário dos professores nesta não forem objeto de reflexão, os atores internos da escola permanecerão estruturados por um dos pilares da cultura da educação nacional: a avaliação com tendência desqualificante. Esta cultura, sustentada pela assimetria dos lugares com relação ao saber e à supervalorização do saber acadêmico, autoriza cada um a se valorizar

vrv

4 Cf. a circular Boissinot-Forestier, no 97-123 de 32 de maio de 1997, publicada no B.O. n 22 de 29 de maio de 1997, * Missão do professor exercendo sua função no ensino fundamental, no colegial geral e tecnológico ou no colegial profissional*, pp.1571-1576. 
rebaixando o outro, a descarregar no escalão hierárquico subordinado tensões e agressões sofridas na instância "superior". Rebaixar o outro a um lugar infantil permite manter para si a ilusão de ser maior e de estar acima da lei comum.

\section{Referências}

Anzieu, D. (1975). Le groupe et l'inconscient. Paris: Dunod.

Barus-Michel, J. (1987). Le sujet social. Paris: Dunod.

Bion, W. R. (1961). Recherches surles petits groupes. Paris: PUF.

Chasseguet-Smirgel, J. (2006). Éthique et estetique de la perversion. Seyssel-sur-le Rhone: Champ Vallon.

Eiguer, A. (1989). Le transferí pervers et la famille. Revue de Psychotherapie Psychanalytique de Groupe, 12, 93-97.

Eiguer, A. (1995). Le cynisme pervers. Paris: L'Hartmann.

Enriquez, E. (1992). L'organisation en analyse. Paris: PUF.

Green, A. (1983). Narcissisme de vie. Narcissisme de mort. Paris: Editions de Minuit.

Kaes, R. (1976). L'apareil psychique groupal. Paris: Dunod.
Kaes, R. (1996). Souffrance et psychopathologie des liens institutionels. Paris: Dunod.

Racamier, P. C. (1970). Le Psychanalyste sans divan:la psychanalyseet les institutions de soin psychiatriques. Paris: Payot.

Racamier, P. C. (1992). Psychanalyse de la psychose. Paris: Payot.

Sirota, A. (1995). Agressions perverses dans les groupes de formations. Revue de Psychothérapie Psychanalytique de Groupe, 24,157-169.

Sirota, A. (1998a). Le travail d'analyseen groupe institué:liaison, déliaison et figures perverses. Thèse de doctorat d'état. Université de Paris 7; 1998.

Sirota, A. (1998b). Des espaces culturesl intermédiaires. Revue Internationale de Psychossociologie, 5 (9), 91-107.

Stoller, R. (1984). La perversión et le desir de faire mal. In J.-B., Pontales. Nouvelle Revue de Psychanalyse, 29: Lechose sexual (pp.163-164). Paris: Gallimard.

Recebido em: 22/10/2007

Versão final reapresentada em: 5/12/2007

Aprovado em: 5/12/2007 